Psychodnalytic

Psychotherapy

Psychoanalytic Psychotherapy

\title{
The impact of organisational change on professionals working within a Community Mental Health Team (CMHT): a psychodynamic perspective
}

\section{Bridget Hanley, Helen Scott \& Helena Priest}

To cite this article: Bridget Hanley, Helen Scott \& Helena Priest (2017): The impact of organisational change on professionals working within a Community Mental Health Team (CMHT): a psychodynamic perspective, Psychoanalytic Psychotherapy, DOI: 10.1080/02668734.2017.1315338

To link to this article: http://dx.doi.org/10.1080/02668734.2017.1315338

\section{Published online: 12 May 2017.}

Submit your article to this journal

Џ Article views: 10

Q View related articles $\square$

View Crossmark data \lceil 


\title{
The impact of organisational change on professionals working within a Community Mental Health Team (CMHT): a psychodynamic perspective
}

\author{
Bridget Hanley*, Helen Scott and Helena Priest \\ Faculty of Health Sciences, Staffordshire University, Stoke on Trent, UK \\ (Received 6 September 2016; accepted 31 March 2017) \\ The aim of this study was to explore the effects of organisational change upon \\ staff working in a Community Mental Health Team (CMHT). A grounded \\ theory methodology was employed to analyse data from eight interviews with \\ a range of staff. Analysis identified one core category and five key categories. \\ 'Corrosion of good work: an ethos in decline' represents the core category \\ and refers to the staff members' sense of demoralisation of their profession- \\ al values and integrity. The first key category, 'Cultural change', refers to \\ staff members' perception of change within the CMHT, with an increased \\ emphasis on regulation, performance management and proceduralisation. \\ Three further key categories were identified: 'Caring clinicians and uncar- \\ ing managers', 'Confusion regarding professional roles' and 'Disconnecting \\ and isolating'. The fifth key 'Staff departing and increasing risk for clients', \\ describes the impact of the working culture. These categories and emerg- \\ ing theory were interpreted through a psychodynamic lens, and identified the \\ need for better management practice, support, training and supervision of \\ staff as the foundations of safe practice.
}

Keywords: Community Mental Health Team (CMHT); organisational change; staff; grounded theory; psychodynamic

\section{Introduction}

The Francis Report (Francis, 2013, p. 13) highlighted a large number of errors, omissions and abuses taking place and an 'unhealthy and dangerous' culture existing within the Mid Staffordshire Hospital Trust, one of the organisations responsible for delivering health care within the UK National Health Service (NHS). In the wake of this report, it is imperative to explore the context and causes of dysfunctional organisational dynamics within the NHS. Staff stress, intergroup conflict and feelings of disgust experienced by staff towards clients are factors that could have influenced the culture of care in this organisation (Whitby \& Gracias, 2013). It is also likely that organisational change may have had an impact upon the working culture. At the time of the report, this particular organisation was attempting to become a Foundation Trust. Foundation Trust status affords greater autonomy to individual NHS Trusts to manage their own finances, systems, and staff, rather

\footnotetext{
*Corresponding author. Email: bridgethanley77@hotmail.com
} 
than these being determined by central government. National targets still apply, but Trusts have greater freedom in how to meet these. Gaining Foundation status requires a Trust to demonstrate it is financially viable, delivers quality services, and has clear governance procedures in place; demands which typically increase the pressure on the organisation. One of the criticisms of the Mid Staffordshire Trust was that in seeking Foundation status, it had become overly preoccupied with financial matters at the expense of clinical care.

Over the past few decades, the NHS more generally has moved from a centralised and integrated service towards a business model dominated by contracting out of services, cost saving, target setting and closer monitoring of staff and activity (Bevan \& Hood, 2006). Wren (2014, p. 19) acknowledges that the NHS is not able to manage staff anxieties when 'the organisational culture in the NHS ... produces insecurity and competition without adequate containment'. Previous research has identified the detrimental effects of organisational change on health staff teams and working practices including increased absenteeism, poor health, increased stress, poor psychological functioning, and low morale (Durdy \& Bradshaw, 2014; Hashmat, Upthegrove, \& Marzanski, 2015; King \& Anderson, 1995). Powell and Morris (2001) acknowledge that such personal experiences of organisational change can indicate problems at a structural level, and the Berwick review (2013, p. 9) linked staff anxiety with patient safety, stating 'fear is toxic to both safety and improvement'.

It is widely acknowledged that working in health services arouses anxiety, pain, and confusion amongst staff members (Ballatt \& Campling, 2014; Hinshelwood \& Skogstad, 2000; Rizq, 2011, 2012a, 2012b, 2013). The work is emotionally demanding, frequently triggering feelings of guilt, blame, dependency and vulnerability (Obholzer, 1994). The concept of social defence was originally developed by Jaques (1953, cited in Whittaker, 2011, p. 482) to refer to 'unconscious collusions or agreements within organisations to distort or deny those aspects of experience that give rise to unwanted emotion'. Menzies Lyth (1959), in particular, revealed how anxiety around working with vulnerable and sick clients led to the creation of social defences by nurses, which became institutionally embedded. Hinshelwood and Skogstad (2000) outline the ways in which organisations are shaped by anxiety and maladaptive social defences that, if left unexamined, can have a detrimental effect on clinical practice (Hinshelwood, 1989; Jaques, 1953; Menzies Lyth, 1959). Furthermore, social institutions represent containers for societal anxieties regarding life and death. The NHS 'is used as a receptacle for the nation's projections of death, and as a collective unconscious system to shield us from the anxieties arising from an awareness of illness and mortality' (Obholzer, 1994, p. 171). Rizq (2011, p. 41) maintains that mental health services defend against 'anxieties relating to psychological vulnerability, dependence, fragility and deeper fears of madness and loss of control'.

Since Menzies Lyth's (1959) study, a number of researchers have employed a psychodynamic perspective to understand how mental health professionals function within the NHS. Hinshelwood and Skogstad (2002) highlighted the defensive techniques utilised by staff within a mental health hostel and medical ward to 
distance themselves from their clients, thus protecting themselves from tension or anxiety. They described how staff related to one another in an excited and flirtatious way as a means of distraction from the pain and suffering of their clients. Morante (2005), too, described a system of psychological defences that protected ward staff from anxieties elicited by their work with clients with acute anorexia. For instance, engaging in more functional tasks such as serving meals and weighing clients diverted the nurses from becoming involved in the more therapeutic (and emotive) role of individual key working.

Kurtz (2001) explored staff organisational defences in forensic mental health settings. Staff experienced anxiety not only in response to the real threat of danger from the clients but also from striving for professional survival within an 'inquiry culture' (p. 71). The staff were aware of significant criticism from several government inquiries into forensic services, which blamed incompetent staff and faulty organisational structures for poor standards of service. This created further pressure on staff to be seen to be performing well in the face of significant pressure from powerful health service managers and society as whole.

Rizq (2011, 2012a, 2012b) used organisational case examples to explore unconscious defence mechanisms within a recently introduced IAPT (Improving access to Psychological Therapies) service. Rizq proposed that IAPT services systematically refute feelings of loss and vulnerability in both staff and clients through promotion of a consumerist ethos and patient choice agenda; the deployment of discourses which minimise notions of fragility and dependence; and bureaucratic and surveillance systems monitoring staff and clinical activity. Rizq (2013) suggested that preoccupations with regulation, surveillance and governance in mental health institutions are symbolic attempts to obtain mastery over feelings of disgust and fear attendant upon working with unwell people.

Ballatt and Campling (2014) have argued that the implementation of incessant change in the NHS keeps at bay 'existential anxieties associated with the uncertainty of sickness, pain and death' (Ballatt \& Campling, 2014, p. 131). The UK coalition government's Health and Social Care Act (2012) implemented further organisational changes within the NHS. Its wider context was the economic crisis and governmental drive towards cutting public expenditure on the NHS, both of which contribute to a backdrop of uncertainty and anxiety for professionals. Rizq (2011) acknowledges that although organisational change can encourage the possibility of creativity, higher levels of risk and uncertainty and the loss of familiar ways of working frequently lead to increased anxiety.

These studies have offered interesting insights into the unconscious dynamics experienced by NHS staff. This study will build on these findings to explore the organisational dynamics of secondary care staff within a Community Mental Health Team (CMHT) during a time of organisational change, with a view to enabling them to work positively within the context of effective provision of services. Anxiety resulting from loss and change can obstruct the effective functioning of staff teams and services (Powell \& Morris, 2001). By gaining an increased understanding of the impact of current organisational changes this study should identify helpful anxiety-containing strategies, thereby promoting a supportive working 
culture, allowing staff to work more positively, and preventing the likelihood of stress or burnout.

\begin{abstract}
Aims
This study aimed to explore the impact of organisational change on mental health professionals working in a Community Mental Health Team (CMHT) in one UK Mental Health Trust. Specifically, it aimed to examine how individuals coped with pressure to change and managed any anxieties resulting from the change process. It also aimed to examine how professionals perceived changes to services and adjusted to accommodate them.
\end{abstract}

\title{
Methodology
}

A grounded theory (Glaser \& Strauss, 1967) methodology was considered most appropriate for this study as it was originally designed to study social processes (Charmaz, 2014; Strauss \& Corbin, 1998). Grounded theory is influenced by symbolic interactionism (Blumer, 1969; Mead, 1934) which considers meanings as originating from interaction and social discourse within the individual's particular culture. In addition, it has previously been used in similar studies exploring staff experiences within an organisational context (Kurtz \& Jeffcote, 2011).

\section{Ethics}

Ethical approval was granted by Staffordshire University, and NHS Research and Development approval was granted by the relevant NHS Trust.

\section{Study site}

The study was conducted within one CMHT in a UK NHS Trust. The staff team comprised nurses, psychologists, support workers, social workers and psychiatrists, working with adults with complex mental health needs. Whilst the service was under similar pressures to other NHS providers, such as lack of resources to meet demand and the expectation to do more with less, they also faced uncertainty about their future. At the time this study took place, there were rumours that the Trust was to be taken over by one of the larger local Trusts, which created some anxiety within the team about what impact this might have on them. The researcher was not known to the team before carrying out the study.

\section{Recruitment and sampling}

The researcher introduced the study at a CMHT meeting to elicit expressions of interest. Those attending were provided with a copy of the participant information 
Table 1. Participant demographics.

\begin{tabular}{lllc}
\hline Pseudonym & Job Role in CMHT & Gender & $\begin{array}{c}\text { Length of service within } \\
\text { CMHT }\end{array}$ \\
\hline Sandra & CMHN & Female & 9 years \\
Michelle & CPN & Female & 19 years \\
Robert & $\begin{array}{l}\text { Cognitive behavioural } \\
\text { therapist }\end{array}$ & Female & 18 months \\
David & $\begin{array}{l}\text { Cognitive behavioural } \\
\text { therapist }\end{array}$ & Male & 2 years \\
John & Psychiatrist & Male & 17 years \\
Jane & Social worker & Male & 10 years \\
Kate & CMHN & Female & 7 years \\
\hline
\end{tabular}

sheet. Due to low attendance, the sheet was also sent to other members of the CMHT. Those expressing interest were provided with a fuller explanation of the study, and the researcher made arrangements to obtain written informed consent prior to conducting face to face interviews. Eight participants were recruited in adherence to the guidance for good standards of qualitative studies (Turpin et al., 1997). All were mental health professionals employed by the NHS and working within a Community Mental Health Team, but ranging in gender, occupation and length of time employed in the service (Table 1).

\section{Data collection}

Semi-structured interviews were conducted in the participants' work environment and lasted between 45 and $60 \mathrm{~min}$. The interviews were recorded using a digital audio recorder.

\section{Data analysis}

A systematic procedure of grounded theory as outlined by Charmaz (2014) was used to analyse the data. In accordance with a theoretical sampling approach, data were gathered strategically, analysing previous data before gathering more. From preliminary analysis, categories, themes and commonalities emerged which then influenced subsequent selection of participants and questions asked in interviews. It was intended that this approach would reinforce and bring to 'saturation' point the most prominent themes. Saturation is a process itself guided by the researcher's developing theoretical understanding and reached when 'new data no longer sparks new insights' (Charmaz, 2008, p. 106). 


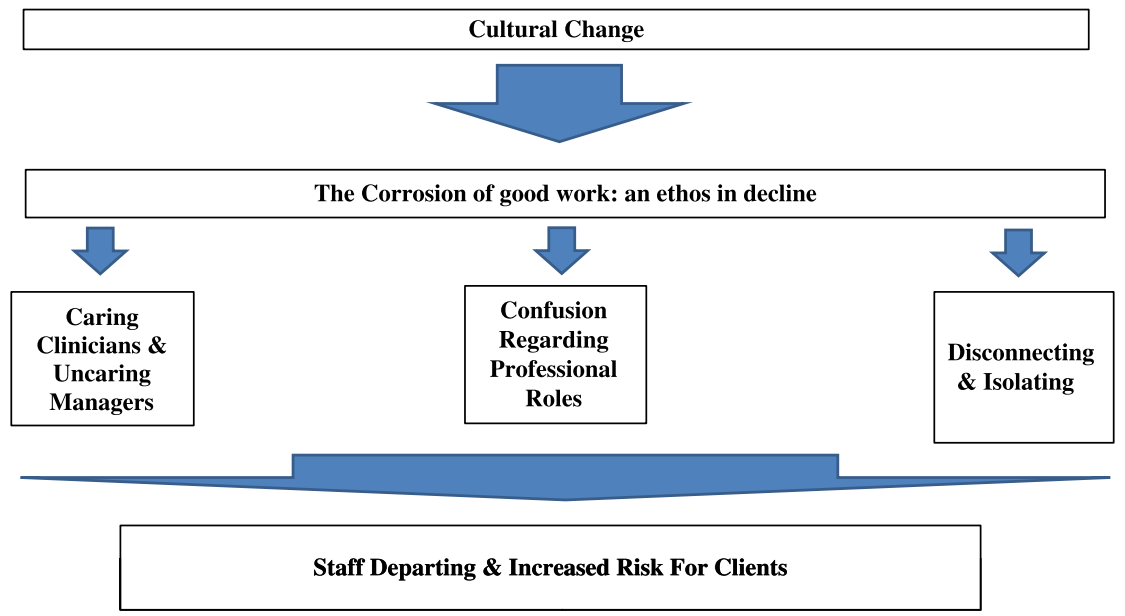

Figure 1. Emerging framework.

Two stages of coding were employed with the aim of developing a theory. Initial coding aimed to identify provisional distinct concepts. Gerunds (verb forms which function as nouns, for example, 'reading') and in vivo coding were employed at this initial stage (Glaser, 1978). In vivo coding is the incorporation of the participants' original phrases and ensures the participant's meaning is preserved. The constant comparative method was used at this point of analysis to form links and observe differences between categories, firstly at different points within the same transcript and then across the data-set, between different interviews. The second stage of analysis comprised focused coding, producing higher order codes from the initial codes which hold more significance or emerge more frequently in the data. At the third, there is a theoretical advancement of the analysis, as the codes are raised to main, then core categories which lifts them from being merely a 'descriptive tool' to a means of synthesising the data ('with abstract power, general reach, analytic direction, and precise wording' (Charmaz, 2008, p. 98)). Memo writing was used to guide the interpretation, and to provide an audit trail of the decision-making process (Tweed \& Charmaz, 2012). A framework was finally produced which illustrated the relationship between the formed categories (Figure 1).

\section{Results}

Analysis identified one core category and five key categories (Figure 1). The core category, 'The corrosion of good work: an ethos in decline' refers to participants' sense of demoralisation and its effects on their professional values and integrity. The first key category, 'Cultural change' refers to the staff perception of change 
within the CMHT with an increased emphasis on regulation, performance management and proceduralisation. In response to the conflict experienced by professionals and the anxieties it generates, three key categories: 'Caring clinicians and uncaring managers', 'Confusion regarding professional roles' and 'Disconnecting and isolating'. The fifth key category, 'Staff departing and increasing risk for clients', describes the impact of the working culture. Psychodynamic ideas, particularly the notion of 'social defenses', were useful in making sense of the data. Psychodynamic ideas are relevant to explore groups and organisations, as many aspects of team working can be shaped and explained by unconscious group processes and 'social defences' (Obholzer, 1994). Grounded theory is similarly useful for studying 'individual processes, interpersonal relations, and the reciprocal effects between individuals and larger social processes' (Charmaz, 2008, p. 83). Anderson (2006, p. 331) maintains they are a 'well-suited partnership' and demonstrates how they can be combined effectively in the interpretation of qualitative data.

\section{Categories}

\section{The corrosion of good work: an ethos in decline}

This core category refers to the sense professionals had that the values and ethos previously associated with the service were being eroded. The 'fantasy' of the NHS as the bearer of communal values was evident, whereby society has projected the 'good' into the concept of an organisation based on principles of kinship and fairness in order to support the vulnerable and sick. This core category encapsulates the sense that the NHS as an organisation is an omnipresent benevolent force and repository of society's 'good' feelings:

\footnotetext{
It is about the service, the NHS as a philosophy, here I can go to the GP any time I want to and I don't have to pay a penny and that is such a fantastic system, I really believe in it. (Kate, Clinical Psychologist)
}

The clinical work professionals do with clients is perceived as representative of this and is viewed as the primary task of the organisation:

$$
\begin{aligned}
& \text {... the most important thing is seeing people and making sure that you're doing a } \\
& \text { good job with them (Robert, Cognitive Behavioural Therapist) }
\end{aligned}
$$

However, analysis revealed that staff perceive the shift in priorities away from the clinical, therapeutic work as dismantling this ethos and undermining the concept of 'good work'. There was a strong acknowledgement that the mental health difficulties people were bringing into clinics were the social consequences of austerity and that this was increasing: 
...people being transferred from DLA, from disability living allowance to personal independence payment or support allowance being rejected, so a whole host of issues that are impacting on people's mental health in every area of life. (John, Social Worker)

Although people approved of the transfer of mental health services into the community, there was a sense that the resources and facilities were no longer there to provide adequate levels of care. The significant gap that was emerging between what could be provided and the level of expectation was expressed:

We're going to make the whole of the country into happy healthy people. I don't know how it's going to happen ... we set up people with this expectation that that's what we're all going to be but the reality is far from it. (Louise, Community Psychiatric Nurse)

A number of participants expressed frustration and also guilt at not being able to provide the care that many of their clients required. There was a sense that they had become the agents of austerity, enforcing cuts and a harsher regime:

so ...now we can only offer a certain amount of sessions ... so I find myself saying 'sorry I can't, we can't give you any more than that' ... and I am saying that 'I am sorry, don't shoot the messenger' (Michelle, Cognitive Behavioural Therapist)

There was recognition by one participant that the culture had undermined staff core values and professional selfhood:

It's a threat to your professional integrity and that's devastating (Kate, Clinical Psychologist)

\section{Cultural change}

This category refers to the culture shift described by staff members who noted a significant increased emphasis on regulation, performance management and proceduralisation in their work. There was a lack of human feeling evident in the participants' descriptions of their daily tasks. They frequently referred to their work using terminology associated with mechanical processes:

Sometimes you just feel like you are getting on with it like a robot, I don't think

it's sustainable for any organisation really, especially when working with a team.

(Sandra, Community Mental Health Nurse)

Many participants referred to the constant recording and monitoring of activities. The sense of competitive drive between professionals in reaching these targets is evident: 
We're sort of all named on the sheets and you see other colleagues who are maybe $100 \%$ but there are always reasons as to why you can't meet those targets ... personally I think we all strive to try and beat 100\%. (John, Social Worker)

Similarly, participants voiced frustration at the increasing standardisation and regulation that was imposed on clinicians, limiting their power to choose appropriate therapeutic intervention for clients:

I guess everything has become more package orientated ... people are being forced to fit into therapies that are perhaps not ideal for them (David, Psychiatrist)

Nearly all the participants reported feelings of conflict between trying to meet the increasing pressure of paperwork and computer work vs. seeing clients and providing therapeutic intervention. There was a sense of frustration at being 'pulled away' (Michelle, Cognitive Behaviour Therapist) from contact with clients, not having time to do what they perceived as the important clinical work and instead feeling that priority was placed on the completion of menial tasks or attending meetings.

We will get asked 'Why haven't you done the CHIPS [the electronic record system in use]? Why's your care plan not there? Why's this piece of paper not in that place?'

... well actually, when somebody's just walked in, in a state of distress, that's what you're dealing with ... that's a struggle all of the time. (Louise, Community Psychiatric Nurse)

One participant felt overwhelmed by the level of administrative tasks and a fear of how this was impacting on their clinical work; they described the sensation as 'spinning plates, just waiting for one to drop off' (Sandra, Community Mental Health Nurse). Another participant voiced a reluctance to see clients if they were not acute, as time taken away from completing the required administrative tasks meant they would experience a 'penalty in paperwork' (David, Psychiatrist). Many participants reflected that the emphasis on the completion of paperwork and meeting targets rather than on patient care was similar to the failures at Mid-Staffordshire:

The focus again is on the payments by results rather than the service we are trying to provide (Sandra, Community Mental Health Nurse)

\section{Caring clinicians and uncaring managers}

Many participants perceived a divide in priorities between management and clinicians. There was a sense that clinicians had the patients' care as their major concern and that there was a shared common purpose to provide treatment to people with mental health problems: 
I think as a team, there are some people who really genuinely want to help clients, as a team it has got to be one of the most caring teams in terms of clients (Michelle, Cognitive Behavioural Therapist)

In contrast, senior managers were perceived as too focused on money and profit making:

I think they are quite detached about what goes on the ground floor, I think overall it's all about the money, it's a business, and patients aren't necessary getting their needs met (Sandra, Community Mental Health Nurse)

One participant reflected on what they perceived as a fundamental flaw in the structure of the NHS; rather than administrative staff being there to support the clinicians it was inverted. They noted that as individuals progressed up the career ladder, they became increasingly removed from clinical work and therefore lost sight of the central task of patient care:

I would say one of the biggest problems is in nursing, OT, social work that to get to succeed career wise and to get to the top grades career wise you become a non-clinician, you become a manager. (Robert, Cognitive Behavioural Therapist)

A number of participants concluded that supervision was no longer valued or perceived as a good use of time by senior managers. One individual reflected on how lack of support for staff members had a clear impact on their ability to sustain their work load:

I apologise now every time I go to one of my managers saying I'm really sorry I know you are busy and one of them was over a quite distressing case, and I still felt this sense of guilt about asking ... people haven't got time for you, they just look really busy (Michelle, Cognitive Behavioural Therapist)

Reflections were repeatedly made that staff mental health was not perceived as significant:

'It's interesting because we're mental health trust aren't we? So we're supposed to be looking after people's mental health so I think you need to be looking after your own staff for your own staff to be able to look after other people (Jane, Community Mental Health Nurse)

Descriptions of a bullying and punitive management culture were evident. Some reflected on how the emergence of a culture of fear and anxiety was very detrimental to staff well-being. One individual commented that punishment undermined productivity and impeded staff ability to provide good patient care: 
I think people don't do their best when they are frightened. Particularly in our job, we need to be secure enough in our job. There is a tipping point when anxiety and stress is helpful but I see it tipping into the side of unhelpful. People are making mistakes. People are forgetting things, and burning out... (Kate, Clinical Psychologist)

\section{Confusion regarding professional roles}

The merging of teams and changing of roles had led to a lack of clarity, with a number of people disclosing uncertainty about what was expected of theirs and others' professional roles:

All of a sudden you wake up in the morning and there's X-team. What does X-team do? Then sometimes their role shifts and ... sometimes they move the goal or change rules.... (Jane, Community Mental Health Nurse)

There was a sense of task drift and a loss of purpose:

I think it's quite difficult at times when the purpose keeps changes, no one is quite sure anymore what we are supposed to be doing, what we are not supposed to be doing. There is always some change happening somewhere. (Sandra, Community Mental Health Nurse)

Although the need for a mix of professionals bringing different ideas and skills sets to the team was acknowledged, there were reflections on the way that the generic care co-ordinator role in teams diminished staff professional identity:

with this new management of change ... trying to sort of wipe away people's different professions ... a social worker, a CPN, an OT, everybody has just become a care coordinator (Jane, Community Mental Health Nurse)

A number of participants described having to compete against other professionals or teams in order to get their voice heard or win their argument. There was a perception of a competitive culture where teams, rather than co-operating, were operating in competition:

I think there's more inter-team rivalries now, I think all teams are more organised and guard their entry points more closely. (David, Psychiatrist)

Experiencing a lack of resources, (for instance, in-patient beds) was often deemed a point of contention between different teams.

you shouldn't be fighting amongst yourselves to get what the patient needs, the patient should have what they need without having to put up half a day's battle trying to find a bed (Sandra, Community Mental Health Nurse) 
There seemed to be a polarisation of views; whilst other teams were deemed problematic and difficult, professionals frequently described their own team in a very positive light:

We do try and pull together and adapt and try and support and help each other out, so that I say thankfully I think it's a good team, we all appear to get on really well. (John, Social Worker)

\section{Disconnecting \& isolating}

The way in which the team was structured and organised was considered to impede communication between professionals and create barriers:

...so patient care is split into little silos with communication between those silos quite difficult and obviously differences of opinions sometimes of how people are managed. (David, Psychiatrist)

The different IT systems used by health and social care was cited as another way in which boundaries between services were exacerbated and acted as a barrier to communication. One person suggested that the team had become too large for the members to assimilate and therefore work well together:

...because the team is in loads of different offices sometimes it can feel like you are actually in different teams. It was interesting because one member of staff asked me 'those at the other end of the office, are we in the same team? (Jane, Community Mental Health Nurse)

This individual reflects on the possibility that retreating into separate spaces and removing themselves from the company of other team members was a consequence of the experience of change:

Maybe that happens during change in dynamics, change in teams and integration that people become set in their environment and their certain desk and at their certain office. (John, Social Worker)

There was a clear sense of isolation and fragmentation expressed by a number of the participants:

We are so segmented now ... and it is harder to meet up as a team, if you didn't walk around the building you probably wouldn't see anyone all day, it feels at times you are working in isolation. (Sandra, Community Mental Health Nurse) 
One individual expressed anxiety that further restructuring would impact on a work relationship which was very supportive in a difficult work environment:

...I think that's what's creating my anxiety a bit more, thinking well they could just whip me away and I have built up a quite good relationship there, working relationship. (Michelle, Cognitive Behavioural Therapist)

Comments were made about how people's manner had changed towards others on the team:

I sometimes think that people are so busy, people perhaps aren't as helpful as they would have been in the past (Sandra, Community Mental Health Nurse)

The following quotation portrays the way in which staff developed an increased individualistic mentality in the face of high levels of pressure and competition:

Everyone in the NHS talks about the frequency and the pace of change, the uncertainty and their fear for their jobs, losing your position or being down-banded ... it created conflict as colleagues were saying 'how can you go up against us?' because everyone tends to, understandably, recoil into that selfishness, look after number one as long as I get my job. (John, Social worker)

\section{Staff departing and increasing risk for clients}

Numerous participants expressed sorrow that staff who had worked in the Trust for a long time were leaving due to the excessive workload, pressure and conflict, often citing burnout or stress as the reason. Experienced staff members were frequently replaced by newly qualified staff, meaning that resources in terms of experience and skills were being lost to the service. There were a number of expressions of sadness that colleagues were leaving, yet an acknowledgement that this was understandable in light of the pressures:

People definitely feel that they are working to capacity and we are still expecting them to take more ... we've had people leaving and really they're leaving because they no longer want to work within the pressures... (Louise, Community Psychiatric Nurse)

As members of staff left, the increasing use of agency staff had a negative impact on the continuity of care and represented an obstacle to the formation of therapeutic relationships. One individual recognised that lack of staff consistency could have a destabilising effect on the patients, with dire results:

...some patients can raise certain alarm bells ... but knowing them, you know what their care plan is, you've spoken to them, they know you as well and that sometimes 
can deescalate them but when they've been speaking to someone they don't know, that can end up with a different end result (Jane, Community Mental Health Nurse)

It was also evident that the excessive pressure on the system was resulting in crises and was putting clients at risk:

.... and they are really buckling under the pressure, and one of the crises I was talking about with a patient we had was because the team was really not coping, because they have massive caseloads now, and you know, when people go into crisis now it is unsafe for people (Michelle, Cognitive Behavioural Therapist)

\section{Summary}

Grounded theory analysis of the data identified six categories. 'The corrosion of good work: an ethos in decline' thus refers to participants' sense of their professional values and integrity being undermined. 'Cultural change' refers to staff perception of emphasis on regulation, performance management and proceduralisation. Alongside the anxiety that system reform generated, conflicting feelings were aroused and their certainty in the intrinsic 'goodness' of their work was shaken. Using a psychodynamic lens to interpret the findings, three unconscious organisational defences were apparent in the work place and labelled 'Caring clinicians and uncaring managers', 'Confusion regarding professional roles', 'Disconnecting and isolating'. The sixth category 'Staff departing and increasing risk for clients' describes the impact of the working culture

\section{Discussion}

Staff within this CMHT perceived a significant cultural shift taking place within the service. They described an increasing bureaucracy and depersonalisation in their work, whereby staff were pulled away from direct contact with their clients. These are instances of the practices outlined by previous researchers (Menzies Lyth, 1959; Morante, 2005; Rizq, 2011), which function as organisational defences against the vulnerabilities and anxiety of working with this client group. The concept of 'virtualism' (Hoggett, 2010; Miller, 2005) refers to how an 'audit surface' stands in for a real relationship with fellow professionals and clients. Relations of conflict between professionals are displaced onto bureaucratic structures, that function as social defences through which regulators project blame onto practitioners for non-compliance, while practitioners project blame onto regulators for excessive bureaucracy (McGivern \& Ferlie, 2007). It appears that ever-increasing bureaucracy acts as an 'anti-task', meaning that the primary task of the organisation (caring for clients) has become too difficult or poorly defined and thus staff members find another task to avoid carrying it out. In this case, therefore, bureaucracy enables staff to avoid face-to-face contact with clients and experiencing the client's pain or vulnerability. According to Hoggett (2010) and Long (2008) this 
represents one of the 'perverse' social defences which occur as a consequence of the regulatory culture now prevalent within public services. According to Long (2008, p. 248), 'perverse social defences' emerge under certain social and organisational conditions, such as individual pleasure at the expense of mutuality; the use of accomplices in an instrumental social relation; and the self-perpetuation or closed-ness of the perverse dynamic.

Ballatt and Campling (2014) describe 'corrupting forces' which are responsible for this 'perverse' culture taking hold in the NHS. Firstly, the promotion of a market economy which has brought into being a commodified view of service requirements at odds with prioritising the needs of vulnerable clients. Secondly, the industrialisation of healthcare, which has heralded a replacement of clinical skills with mechanical processes and systems such as manualised on-line therapy. Thirdly, excessive regulation and performance management. They argue that a disproportionate focus on these activities fosters a culture of suspicion in public sectors.

However, the findings of this study highlight that staff are aware of and averse to this cultural shift and perceive the core values of 'good work' as being eroded by 'perverse' incentives of reaching targets and completing paper work. There was a sense of the guilt and betrayal expressed by the CMHT staff in having to marketise the health sector, which appears to go against the principles and values they believe the NHS (and they) stand for. As a consequence of these overwhelming feelings, which were difficult to manage, unconscious defences were apparent. Splitting was evident, which enabled the professionals to maintain their association with the good object and project difficult and guilty feelings onto management. Management was thus perceived as insensitive to client and staff needs, bullying and uncaring, while clinicians were deemed as caring and compassionate. Inter-professional rivalries and conflict emerged, and further splitting was evident in the way that staff members regarded their own teams as 'good', whilst seeing other teams as 'bad'. Dissociation and cutting off were also apparent, as many staff voiced their sense of disconnection from each other within the CMHT whilst having feelings of rivalry and opposition for other teams. This frequently escalated into people no longer investing emotionally in their role and ultimately leaving, which in turn impacted on patient care.

\section{Clinical implications}

This study has met its aim of analysing how individuals in CMHTs respond to organisational change, using a psychodynamic framework to interpret data and thereby identify social defences. It has also met its objectives of exploring links between organisational change and anxiety, and considering how change could be managed to mitigate these negative effects. The findings of this study suggest, therefore, that greater consideration should be given to the way in which rapid change and restructuring of mental health services dismantle the containing 
aspects of the organisation, resulting in defences and polarised perceptions in staff. The practical implications suggest that there is a need for a better balance between work structures and systems, and the needs of individuals. As Kennedy (2013) suggests, this could be achieved by focussing on compassionate care rather than service pathways and performance targets. Informed by the findings of the current study, psychologists might be able to undertake support work with CMHTs, for example by helping clinicians and managers to understand each others' roles and pressures. Staff might then feel better contained and able to function better as a group, as staff support, training, supervision and health needs are the foundation of safe practice. Wren's $(2014$, p. 20) recommendations for anticipating and managing psychological challenges for health care staff working in the NHS are thus endorsed:

- Providing space for reflection (e.g. adopting a Schwartz Centre round model and promoting other forms of reflective practice).

- Exploring with management and staff whether work design promotes adaptive defences.

- Consciously paying attention to the content of the work, its emotional impact and the structure and designs of jobs, roles and teams.

- Paying attention to the processes supporting the work, (meetings, supervision, and management of risk).

- Ensuring that skills and resources of management at every level are treated as being of crucial importance.

\section{Limitations}

Although work has been done within primary mental health services (Rizq, 2011, 2012a, 2012b, 2013), there is a gap in the current knowledge base relating to secondary care, which this study partly addresses. The author did not interview senior managers, which would be useful to verify whether they were aware of staff perceptions and to ascertain their own attitudes to staff vulnerability. Although the eight interviews provided a wealth of data, it is possible that saturation point was not reached. However, in line with Dey's (1999) suggestion that the concept 'saturation' is imprecise, this study has aimed for 'theoretical sufficiency': categories are suggested, rather than saturated, by the data. As with any qualitative research with a small sample, carried out at a particular time, caution must be exercised in extrapolating general implications from these findings. Nevertheless, the study does appear to contain a significant degree of 'theoretical transferability' as findings of this study were shown to be consistent with previous research carried out in this area. Therefore, despite its small scale, there is scope for transfer of the findings beyond this particular study setting. 


\section{Conclusion}

Menzies Lyth (1959) argued that healthcare staff defended against feelings of vulnerability by becoming emotionally detached from clients. Similarly, the findings of this study suggest that secondary mental health services appear to be defending against the vulnerability of their own staff and clients through the implementation of increased bureaucracy, which depersonalises their work. However, this study has also highlighted that staff perceive kindness as central to their work with clients, encapsulated in the term 'good work', with clients seen as vulnerable and deserving of the staff's efforts. The impact of cuts to funding, increasing regulation, accountability and industrialising therapy is creating a significant challenge to the ethos of caring and trust. As a consequence, staff experience a sense of diminished professional values and low morale. Defences that emerged included splitting, whereby management are perceived as cut off, lacking understanding or even neglecting of these needs whilst clinicians are deemed as compassionate. Inter-professional rivalry and conflict and dissociation and isolation are also in evidence. The consequences highlighted in this study include increased risk to client safety and staff wellbeing, and high staff turnover.

\section{Acknowledgements}

The authors would like, in particular, to thank one of the staff members (who wished to remain anonymous), who was instrumental in facilitating this research.

\section{Disclosure statement}

No potential conflict of interest was reported by the authors.

\section{References}

Anderson, J. (2006). Well-suited partners: Psychoanalytic research and grounded theory. Journal of Child Psychotherapy, 32, 329-348.

Ballatt, J., \& Campling, P. (2014). Intelligent kindness: Reforming the culture of healthcare. London: RCPsych publications.

Berwick, D. (2013). A promise to learn, a commitment to act: The Berwick Review into Patient Safety. National Advisory Group on the Safety of Patients in England. London: Department of Health. Retrieved from http://www.gov.uk/government/uploads/system/uploads/attachment data/file/226703/Berwick_report.pdf

Bevan, G., \& Hood, C. (2006). What's measured is what matters: Targets and gaming in the English public health care system. Public Administration, 84, 517-538.

Blumer, H. (1969). Symbolic interactionism. Englewood Cliffs, NJ: Prentice Hall.

Charmaz, K. (2008). Grounded theory. In J. Smith (Ed.), Qualitative psychology: A practical guide to research methods (pp. 81-110). London: Sage.

Charmaz, K. (2014). Constructing grounded theory. London: Sage.

Dey, I. (1999). Grounding grounded theory. San Diego, CA: Academic Press.

Durdy, H., \& Bradshaw, T. (2014). The impact of organisational change in the NHS on staff and patients: A literature review with a focus on mental health. Mental Health Nursing, 34, 16-20. 
Francis, R. (2013). Report of the Mid Staffordshire NHS Foundation Trust public inquiry. Executive summary. London: The Stationery Office.

Glaser, B. (1978). Theoretical sensitivity: Advances in the methodology of grounded theory. Mill Valley, CA: Sociology Press.

Glaser, B., \& Strauss, A. (1967). The discovery of grounded theory. New York, NY: Aldine de Gruyter.

Hashmat, H., Upthegrove, R., \& Marzanski, M. (2015). Impact of functionalisation on staff morale in CMHTs. Progress in Neurology and Psychiatry, 19, 24-27.

Hinshelwood, R. D. (1989). A dictionary of Kleinian thought. London: Free Association Books.

Hinshelwood, R. D., \& Skogstad, W. (2000). Observing organisations: Anxiety, defence, and culture in health care. London: Bruner Routledge.

Hinshelwood, R. D., \& Skogstad, W. (2002). Irradiated by distress: Observing psychic pain in health-care organizations. Psychodynamic Psychotherapy, 16, 110-124.

Hoggett, P. (2010). Government and the perverse social defence. British Journal of Psychotherapy, 26, 202-212.

Jaques, E. (1953). On the dynamics of social structure a contribution to the psycho-analytical study of social phenomena. Human Relations, 6, 3-24.

Kennedy, A. (2013). A compassionate formulation of task drift in mental health staff. Mental Health Review Journal, 18, 73-82.

King, N., \& Anderson, N. (1995). Innovation and change in organisations. London: Routledge.

Kurtz, A. (2001). A psychodynamic view of two forensic mental health services. Criminal Behaviour and Mental Health, 12, S68-80.

Kurtz, A., \& Jeffcote, N. (2011). Everything contradicts in your mind': A qualitative study of experiences of forensic mental health staff in two contrasting services. Criminal Behaviour and Mental Health, 21, 245-258.

Long, S. (2008). The perverse organisation and its deadly sins. London: Karnac.

McGivern, G., \& Ferlie, E. (2007). Playing tick-box games: Interrelating defences in professional appraisal. Human Relations, 60, 1361-1385.

Mead, G. (1934). Mind, self and society. Chicago, IL: University of Chicago Press.

Menzies Lyth, I. (1959). The functioning of social systems as a defence against anxiety. Human Relations, 13, 95-121.

Miller, D. (2005). What is best 'value'? Bureaucracy, virtualism and local governance. In P. Du Gay (Ed.), The values of bureaucracy (pp. 233-254). Oxford: Oxford University Press.

Morante, F. (2005). Applying psychodynamic thinking in a staff support group to reflect on service change and clinical practice in a specialist psychiatric service. Psychodynamic Psychotherapy, 19, 103-120.

Obholzer, A. (1994). Managing social anxieties in the public sector. In A. Obholzer \& V. Z. Roberts (Eds.), The unconscious at work: Individual and organisational stress in the human services (pp. 169-178). London: Routledge.

Powell, S., \& Morris, A. (2001). Loss and change in primary care: Working with organisational anxiety. Psychodynamic Psychotherapy, 15, 207-223.

Rizq, R. (2011). IAPT, anxiety, and envy: A psychodynamic view of NHS primary care mental health services today. Public Sector Practice, 27, 37-54.

Rizq, R. (2012a). The ghost in the machine: IAPT and organizational Melancholia. British Journal of Psychotherapy, 28, 319-335.

Rizq, R. (2012b). The perversion of care: Psychological therapies in a time of IAPT. Psychodynamic Practice, 18, 7-24.

Rizq, R. (2013). States of abjection. Organization Studies, 34, 1277-1297. 
Strauss, A., \& Corbin, J. (1998). Basics of qualitative research. Techniques and procedures for developing grounded theory. Newbury Park, CA: Sage.

Turpin, G., Barley, V., Beail, N., Seaire, J., Slade, P., Smith, J. A., \& Walsh, S. (1997). Standards for research projects and theses involving qualitative methods: Suggested guidelines for trainees and courses. Clinical Psychology Forum, 108, 3-7.

Tweed, A., \& Charmaz, K. (2012). Grounded theory methods for mental health practitioners. In A. R. Harper \& D. Thompson (Eds.), Qualitative research methods in mental health and psychotherapy: A guide for students and practitioners (pp. 131-146). Chichester: John Wiley \& Sons Ltd.

Whitby, P., \& Gracias, S. (2013). Reflecting on the Francis report: This has happened before. Clinical Psychology Forum, 249, 13-17.

Whittaker, A. (2011). Challenges for the Munro review? Journal of Social Work Practice, $25,481-495$.

Wren, B. (2014). Managing staff experience to improve organisational culture. Implementing culture change within the NHS: Contributions from organisational psychology. Occupational psychology in public policy (OPIPP) Group Report. Retrieved from https://www.bps.org.uk/system/files/userfiles/Division\%20of\%200ccupational\%20 Psychology/public/17689_cat-1658.pdf 